\title{
Development of Fire-Resistant Multilayer Materials for Working Clothes of Welders
}

\author{
Zaure Dauletbekovna Moldagazhiyeva ${ }^{1} \&$ Raushan Orazovna Zhilisbayeva ${ }^{1}$ \\ ${ }^{1}$ Almaty Technological University, Kazakhstan \\ Correspondence: Zaure Dauletbekovna Moldagazhiyeva, Almaty Technological University, 100, Tole bi Street, \\ 050012, Almaty, Kazakhstan.
}

Received: October 5, 2014

Accepted: October 15, 2014

Online Published: July 31, 2015

doi:10.5539/mas.v9n8p334

URL: http://dx.doi.org/10.5539/mas.v9n8p334

\begin{abstract}
In the paper several types of multilayer materials are proposed, which consist of fire-resistant woven and nonwoven materials. The developed non-woven material is a fabric made from woolen and $\mathrm{m}$-aramide fibers connected in a combined way and which are components of a new multilayer material for welder's uniform. The proposed new woven materials due to their specific properties are suggested for an application as internal layers of protective clothing. Several types of fire-resistant fabrics with improved service properties are studied.
\end{abstract}

Keywords: Non-woven material, multilayer materials, working clothes, wool, aramid fibers

\section{Introduction}

Light industry development program in the Republic of Kazakhstan for 2010-2014 years is a step in an implementation of activities for a development of competitive consumer goods of high quality and wide variety (Program, 2010)

Development of scientific and technical progress, transformation in a field of production at modern industrial enterprises prioritized a task of an optimal solution of industrial safety problem, including a development of working clothes for protection from harmful effects of industrial environment

For a long time in a design of working clothes a major approach was functional-economic approach, in which the maximum unification of structure, its details, parts and elements minimized expenses of industrial enterprises related with provision (free of charge distribution) of working clothes to employees, working in various branches of the economy (Mokeeva, Picinskaya, 2013) .

At a pre-project analysis phase a problem was indicated - lack of working clothes for welders on market, which would fully meet consumers requirements. Currently, there are several companies in Kazakhstan, which produce working clothes: "KazCentre", " Master-Spec ", "WorkClothers", "Amirsana", "Modni rabotnik" (Stylish worker), "Altyn Zhuldiz", etc. The majority of these enterprises uses canvas made from half-linen fabric with fire-protective treatment or special cotton fabrics soaked with a special fire-retardant treatment, at the same time those materials are not effective from the point of view of their heat-resistance: they deteriorate in 4 to 6 months instead of required 12 months, also their manufacturing process is labor-intensive.

In spite of the presence on the market of a diversity of fabrics and materials with special finishing for protection from extreme temperatures, enterprises, producing costumes for welding, do not fully use new materials in because of high cost in case high performance properties and, backwards, use low performance materials with an affordable cost.

That's why a supply of working clothing to Kazakhstan market is economically profitable and improvement of its quality is an important scientific and industrial problem.

On of the promising direction in a production of fire-protective nonwoven materials are materials, produced from chemical and synthetic heat-resistant fibers.

\subsection{Review of Fire-Protective Materials}

Nowadays there is a big number of fire-protective materials. Methods of their production vary from soaking a fabric with special compositions to a creation of new materials from non-inflammable fibers and threads. Nowadays special chemical fibers had become widely spread, thus transfering scientific advances to industry. 
Properties of the fibers such as high strength, thermal stability, chemical stability, fire resistance, non-inflammability, electrical conductivity, shock resistance and light weight make them and products based on them necessary and irreplaceable in various branches of industry, including textile industry (Zhilisbayeva, \& Kozhabergenova, 2012).

Many foreign and domestic companies are developing fire-protective materials, which have standard mechanical and thermal and physical properties. However, it's worth mentioning, that high cost is a significant disadvantage of imported materials, and materials, produced by domestic companies, do not alway meet requirements of complex protection from harmful industrial factors, in particular, they are not fire-resistant.

Variety of fire-protective materials on international market allows to select a fabric for welder's working clothing, which have a certain set of characteristics, which will allow to use it in different companies. One of the leading Russian companies producing fabric for working clothing and uniform is "Chaikovski textil'" INC., which produces "Phenix" (Phoenix) brand of fabric with fire-resistant treatments TEFLON and PYROVATEX, which are produces by CIBA company (Fomchenkova,2002). Russian company "Kadoteh" produces fire-resistant fabrics from Nomex thread (produced by DuPont) and working clothes from it (Gushina, 2004). Westex concern produces INDURA and INDURA UltraSoft brands of fabric, which use PROBAN treatment. INDURA fabric is produces from cotton fibers with $240-472 \mathrm{~g} / \mathrm{m}^{2}$ density. In a case of INDURA UltraSoft production, small amount (12\%) of polyamide (nylon) fibers with $190-405 \mathrm{~g} / \mathrm{m}^{2}$ density are added to cotton fibers, which constitute the major part (88\%). An addition of nylon increases service life of clothing up to $50 \%$ and increases protection properties of the fabric. Fabrics protect from electric arc, open fire, splashes of melted metal and are designated for oil and gas industry workers, power engineering specialists, welders, metallurgist and other applications (Ognezashitnie materialy Westex (USA), 2005).

Weldersafe $100 \%$ cotton fabric $\left(420 \mathrm{~g} / \mathrm{m}^{2}\right)$ provides an absolute protection from burning injury of 3 level during the test with open fire and also protects from splashes of meltd metal and sparkles. The fabric is recommended for an application in welder working clothing (Rabochaya odezhda, 2004). «Klopman» company produces fire-resistant fabrics for working clothing and uniforms, which protect from fire and melted metal (cotton, mixed (Fabrics Klopman, 2005). Russian company «Baltiiski textil'» is on the biggest produces of fabrics for working clothing, uniform and camouflage on Russian market. XM FIRELINE fabrics are produced from $100 \%$ high-quality cotton (Gefest-420) for manufacturing of working clothing for welders and metallurgist (Colombo-350), workers in oil and gas industry and power engineering speialists (Etna-350, Electra-320, 420, Madeira-320) («Baltiiski textil'», 2014). Also, textile materials with treatment based on greycoat cloth (Zhilisbayeva, 2011), which have several disadvantages such is high surface density (weight) and that a treatment can be washed off during use of working clothing.

Studying of working conditions in aforementioned industries, many foreign and domestic companies develop fire-protective materials, which have standard mechanical and thermal and physical properties. However, it's worth mentioning, that high cost is a significant disadvantage of imported material and materials, produced by domestic companies, do not alway meet requirements of complex protection from harmful industrial factors.

Until recently in Kazakhstan, as a rule, the most necessary and primitive textile materials and protection methods were used. In particular, in the case of working clothing production, a development was directed at use of inexpensive fabrics of natural and synthetic origin, which protective properties were determined by a fabric's thickness, weight and type of treatment. At the same time, new synthetic and artificial protective materials with improved protection, technological and consumer properties had become accepted in the world.

Nonwoven industry is the one of the most dynamically developing industries in the world. The most important point in the rapid development and commercialization of nonwoven materials is an ability to produce materials with special properties in the shortest time and with an affordable price (Scott, 2005).

The considerable part of all textile materials is nonwoven linens, which successfully compete with fabrics and substitute them, because they posses significant advantages (high productivity, an ability to reduce a production cycle, expenses of money and labor, maximum possible replacement of natural fibers with artificial ones).

\section{Methodology}

After complex analysis of the most acceptable textile material used as a protective layer for welder's working clothing, it was established, that the most heat-resistant and economically feasible are nonwoven materials, produced from wool and aramid fibers.

Technical effect of set objective consists of widening raw materials range for manufacturing of nonwoven and fire-resistant material with an implementation of low-grade wool fibers of sheep, bred in Kazakhstan, and, in the 
same time, of utilization of textile industry waste materials. From the point of view of flammability, wool is incombustible in comparison with regular fibers and it has low flame temperature (from 600 to $1000 \boldsymbol{E C}$ ) (Scott, 2005).

Mixing of meta-aramid fibers with wool fibers and their binding by needle punching provides an increase of thermal stability, watertightness and a decrease of thermal conductivity evenly along whole volume of produced material, which increase a protective capability of produced material.

Needle-punching is the most widely spread method of nonwoven materials production in textile industry in the world (Kamath et al., 2004).

That kind of nonwoven materials are produced using needle-punching equipment. Binding of fibers in nonwoven linen is conducted by mechanical mixing with repeated punching of nonwoven linen with notched needles. When they pass through linen, needles take bundles of fibers with notches and pull them through the thickness of linen. In results position an orientation of fibers in linen are changed. In the positions of punches bundles of fibers perpendicular to a linen's plate are formed and with a help of that bundles binding of linen's elements is conducted, which increase strength of the material.

An implementation of wool fibers in the discussed method allows to traditionally bind the material by fulling, which increase thermal stability, watertightness and decrease thermal conductivity (Suharev, 1973).

In order to obtain the best combination of physical, chemical and consumer properties of a nonwoven material in a corresponding segment, it is necessary to select a structure of material and method of its formation. In the same time, a structure of fibrous layer (linen), as a rule, is characterized by thickness of web, number of web's additions, unevenness of the web, ratio of various fibers in a mix, composition of a fibers, position of fibers (coefficient of straightness and extent, orientation angle), length of fiber, diameter of fiber, fiber distribution along thickness, presence or absence of frame layer, its structure, density of punches, depth of punches, presence of binder and adhesion bonds.

On the basis of the conducted studies optimal methods of new nonwoven materials production are selected, which includes such operations as preparation and mixing of fibers, greasing, combing, formation of fibrous layer, needle punching, calendering, heat shrinkage, and can be characterized by effectiveness of raw materials loosening, effectiveness of scutching, composition of emulsion and binder, coefficient of fiber distribution's unevenness, speed of web, linear speed of a linen's movement, temperature of thermal treatment, etc. Those specimens were produced using fulling, needle-punching and combined methods.

Mixed production of nonwoven linens consists of mixing of wool and aramid fibers on an initial stage of linen's production,

Combined technology of nonwoven linen's production is based on a combiantion of mechanical and physicochemical methods of binding in form of layer of wool and aramid fibers. Combinations of methods can vary: for example, initial linen binding by needle punching or jet-stream and consequent binding with binder, broaching of frame by fleecy threads and their binding by means of binder reagents, etc. Also, jet-stream processing of linen, containing fusible fibers, fibrids or biocompnent fibers by hot air or water, can be attributed to a combined method. At that, not only linen fibers' entaglement takes place, but also their thermal binding (Sheromova, 2006). In the table 1 examples of testing specimens of nonwoven material, which differ in number of layers, weight and production method are presented.

Table 1. Examples of obtained specimens of nonwoven fire-protective linens

\begin{tabular}{|c|c|c|c|c|c|}
\hline No & $\begin{array}{l}\text { Composition } \\
\text { of layers }\end{array}$ & $\begin{array}{l}\text { Temperature inside the } \\
\text { fabric after high } \\
\text { temperature treatment }\end{array}$ & $\begin{array}{r}\text { Ratio of } \\
\text { componenets, } \\
\text { mass. } \% \\
\end{array}$ & $\begin{array}{l}\text { Method of } \\
\text { production }\end{array}$ & $\begin{array}{l}\text { Thickness of } \\
\text { specimens, mm }\end{array}$ \\
\hline \multirow[t]{2}{*}{1} & M-aramide & 53 & 50 & combined & 20 \\
\hline & Wool & & 50 & & \\
\hline \multirow[t]{2}{*}{2} & M-aramide & 52 & 60 & mixed & 15 \\
\hline & Wool & & 40 & & \\
\hline \multirow[t]{2}{*}{3} & M-aramide & 50 & 70 & mixed & 25 \\
\hline & Wool & & 30 & & \\
\hline \multirow[t]{2}{*}{4} & M-aramide & & 70 & combined & 25 \\
\hline & Wool & 45 & 30 & & \\
\hline
\end{tabular}




\begin{tabular}{llllll}
\hline \multirow{3}{*}{5} & M-aramide & & & & 18 \\
M-aramide & 47 & 60 & combined & \\
Wool & & 40 & & 30 \\
M-aramide & & 60 & combined & \\
M-aramide & 49 & 40 & & \\
Wool & & & & \\
M-aramide & & & \\
Wool & &
\end{tabular}

Study of the micro structure of nonwoven was conducted with an implementation of «MC-300TX» trinocular microscope. The view of testing specimens is presented on figure 1 .

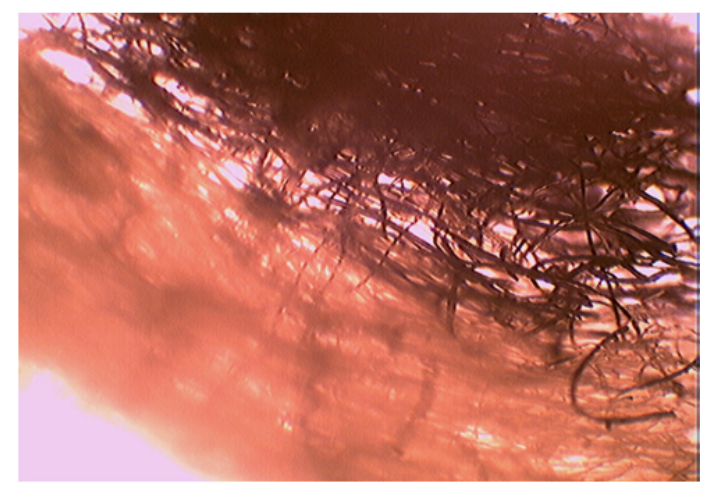

a) $\times 4000$

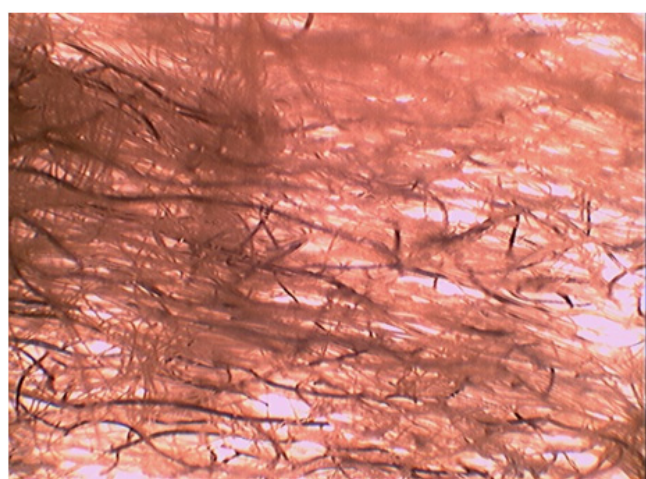

b) $\times 4000$

Figure 1. Microstructure of testing specimens of nonwoven fire-resistant linens: a) Specimen produced with combined method; b) Specimen produced with mixed method.

Figure 1a shows a prototype produced in a combined way, in the form of layers of woolen and meta-aramid fibers. Figure $1 \mathrm{~b}$ shows a sample of the resulting mixed manner in the form of entanglement of wool and meta-aramid fibers.

Note the high degree of interlinkage fibers together, which has a positive effect on improving the physical and mechanical properties of fire-resistant nonwoven fabric as a whole.Thickness of fibers is: m-aramid - 12 microns, wool - 25 microns.

\section{Results}

According to the results of investigation on a dependence between weight and number of layers, as well as various ways of nonwoven materials production, it was established, that the optimal way of new nonwoven materials' production is combined method, because of optimal parameters of a worker's protection from high temperature, in particular, acceptable temperature specified by standards, on an inner side of linens.

Working clothing from new generation materials is of course 3-4 times more expensive than regular one, but higher then traditional canvas (3-4 months) welder's working clothing actual service life, as well as essentially new level of protective, mechanical, aesthetical and performance parameters of new materials must perceive customers to use working clothing from that type of fabrics (Nonwovens \& Technical Textiles, 2007).

During a design of welder's working clothing it is proposed to use known fire-resistant materials as additional protective pieces and outer layer, which characteristics are presented in table 2 . 
Table 2. Main properties of analogue materials

\begin{tabular}{|c|c|c|c|c|}
\hline \multirow{2}{*}{$\begin{array}{l}\text { Properties and characteristics, } \\
\text { units of measurement } \\
\text { Name of the material }\end{array}$} & \multicolumn{4}{|c|}{ Values of properties and characterisitcs of the meaterial } \\
\hline & Premier FR 350A & $\begin{array}{l}\text { FlameFort } \\
\text { W280 Protect }\end{array}$ & Brezent OP & FlameFort 210A \\
\hline Code number & $10202 \mathrm{AM}$ & $50402 \mathrm{~K} 14$ & 11255 & 60405 a-M \\
\hline Composition of fibers & $\begin{array}{l}100 \% \text { cotton }+ \text { antistatic } \\
\text { thread }\end{array}$ & $100 \%$ aramide & $\begin{array}{l}60 \% \text { flax }+40 \% \\
\text { cotton }\end{array}$ & $\begin{array}{l}100 \% \text { aramide }+ \\
\text { antistatic thread }\end{array}$ \\
\hline Surface density, $\mathrm{g} / \mathrm{m} 2$ & 340 & 430 & 495 & 220 \\
\hline Weave & Satinlike $5 / 2$ & Satinlike & Reps & Serge $2 / 1$ \\
\hline Treatment & PyrovatexTo $+\mathrm{HMBO}$ & K14 & $\mathrm{OP}$ & HMBO \\
\hline Breaking load (base/weft) & $1200 \mathrm{~N} / 700 \mathrm{~N}$ & $\begin{array}{l}1200 \mathrm{~N} / \\
1200 \mathrm{~N}\end{array}$ & $1400 \mathrm{~N} / 700 \mathrm{~N}$ & $1000 \mathrm{~N} / 800 \mathrm{~N}$ \\
\hline
\end{tabular}

For a characterization of fire-protective fabrics from functinal protection point of view, it is necessary to conduct a series of studies, which will be proving their suitability for an application as a protection from high temperatures and melted metal. The first step in a selection of working clothing is a determination of danger, evaluation of the impact's potential and level of protection (Golubaev, 2008).

Resistance to splashes of melted metal and fire-resistance are main indicators of welder's protective clothing's quality.

Considering that topography of melted metal splashes during welding varies and at the same time sparkles and splashes hit at various angles, it was proposed to study materials resistance to inflammation.

\subsection{Inflammability Tests}

Combustion is oxidation chemical reaction occurring at fast rate, which is accompanied by light and heat emission. An initial moment of combustion, which occurred due to open flame action, is called inflammation (Kel'bert, 1971).

According to that, studies were conducted on «OVT» equipment using GOST 50810 (GOST50810-95) standards. The standard specifies a method of determination of textile materials (fabrics, nonwoven linens) capability to resist inflammation, steady combustion, as well as evaluation of their fire-resistant properties. For tests, specimens of $220 \times 170 \mathrm{~mm}$ sizes were fabricated, 8 in a direction of warp (along the length) and 8 in a direction of weft (along the thikness).

Before testing, specimens were conditioned with temperature of $(20 \pm 2){ }^{\circ} \mathrm{C}$ and relative humidity of $(65 \pm 2) \%$ during 24 hours. During tests from a surface, a burner is positioned in a horizontal direction $40 \mathrm{~mm}$ higher than lower edge of a specimen and moved to a specimen on $17 \mathrm{~mm}$ distance. During tests from an edge, a burner is positioned in $60^{\circ}$, in order to make flame touch lower edge of a specimen. Time of exposure for a new specimen is $5 \mathrm{sec}$. In a case of testing steady combustion, time of exposure to flame is increase to $15 \mathrm{sec}$.

Tests showed that the materials belong to flame-resistant fabrics.

Results of inflammability tests of analogue materials are presented in table 3.

Table 3. Results of the classification trials of materials (on warp)

\begin{tabular}{lllll}
\hline & \multicolumn{3}{l}{ Name of the material } & \\
\cline { 2 - 5 } Type of tests & Premier FR 350A & FlameFort W280 Protect & Brezent OP & FlameFort 210A \\
Time of ignition from a surface, sec & 15 & 15 & 11 & 15 \\
Time of ignition from an edge, sec & 15 & 15 & 15 & 15 \\
Time of independent combustion, sec & & & & \\
& 0 & 0 & 0 & 0 \\
Burnout to an edge & No & No & No & No \\
Inflammation of cotton wool & No & 12 & No & No \\
Length of charred area, mm & 19 & & 35 & 22 \\
\hline
\end{tabular}


Table 4. Results of the classification trials of materials (on weft)

\begin{tabular}{|c|c|c|c|c|c|c|}
\hline \multirow{3}{*}{ Type of tests } & \multicolumn{6}{|c|}{ Name of the material } \\
\hline & Premier & FR & FlameFort & W280 & Brezent & FlameFort \\
\hline & $350 \mathrm{~A}$ & & Protect & & OP & $210 \mathrm{~A}$ \\
\hline Time of ignition from the surface, sec & 15 & & 15 & & 11 & 15 \\
\hline Time of ignition from an edge, sec & 15 & & 15 & & 15 & 15 \\
\hline Time of independent combustion, sec & 0 & & 0 & & 0 & 0 \\
\hline Burnout to an edge & No & & No & & No & No \\
\hline Inflammation of cotton wool & No & & No & & No & No \\
\hline Length of charred area, $\mathrm{mm}$ & 25 & & 19 & & 42 & 27 \\
\hline
\end{tabular}

Diagram of the test results is presented on Figure 2.

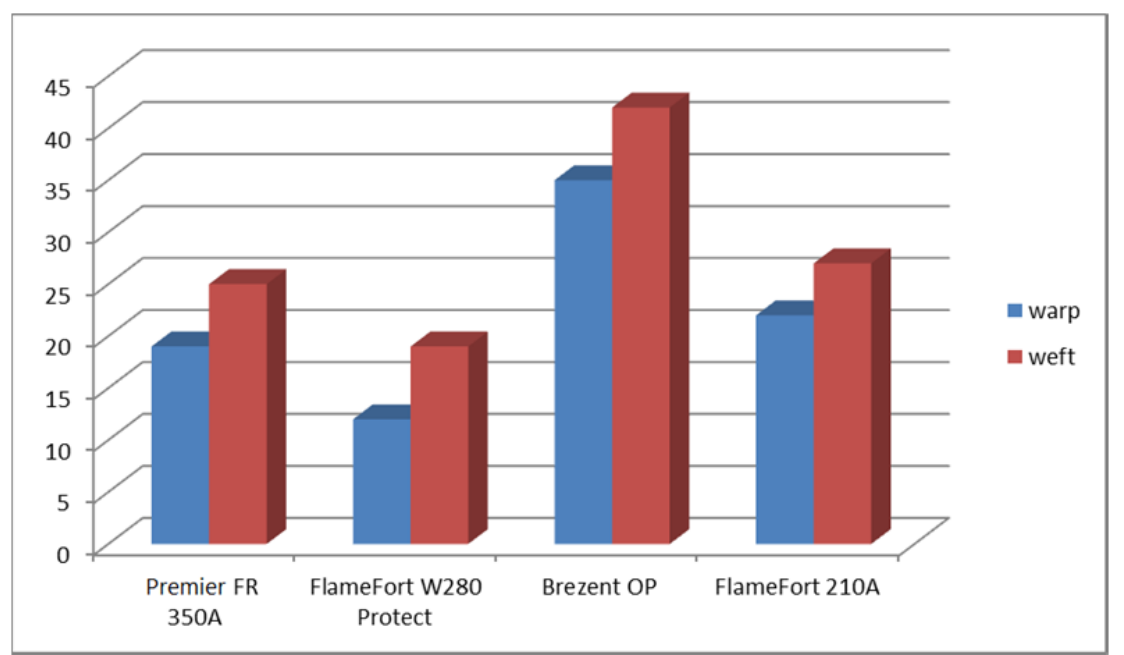

Figure 2. Resistance to burning along length of charred area

Results of the studies allowed to establish, that Brezent OP material has low resistance to burning, Premier FR 350A and FlameFort 210A didn't demonstrates signs of combustion.

After numerous experimental studies, an optimal compostion of layers of multilayer material, which are resistant to high temperatures, was determined.

Table 5 .

\begin{tabular}{|c|c|c|c|}
\hline No & $\begin{array}{l}\text { Composition of layers of } \\
\text { multilayer material }\end{array}$ & $\begin{array}{l}\text { Surface } \\
\text { density, } \mathrm{g} / \mathrm{m} 2\end{array}$ & $\begin{array}{l}\text { Fire-resistance } \\
\text { (Oxygen index), \% }\end{array}$ \\
\hline \multirow[t]{3}{*}{1} & FlameFortW280 Protect & 430 & \\
\hline & Premier FR 350A & 340 & 37.4 \\
\hline & Nonwoven material M-Sh (20) & 200 & \\
\hline \multirow[t]{3}{*}{2} & FlameFortW280 Protect & 430 & \\
\hline & Premier FR 350A & 340 & 38.0 \\
\hline & $\begin{array}{l}\text { Nonwoven material M-Sh-M } \\
\text { (25) }\end{array}$ & 150 & \\
\hline \multirow[t]{3}{*}{3} & FlameFort W280 Protect & 430 & \\
\hline & Premier FR 350A & 340 & 38.2 \\
\hline & $\begin{array}{l}\text { Nonwoven material M-Sh-M } \\
(1.8)\end{array}$ & 140 & \\
\hline \multirow[t]{3}{*}{4} & FlameFortW280 Protect & 430 & \\
\hline & Premier FR 350A & 340 & 38.1 \\
\hline & $\begin{array}{l}\text { Nonwoven } \\
\text { M-Sh-M-Sh (30) }\end{array}$ & 305 & \\
\hline
\end{tabular}


Thus, optimal layers composition of multilayer fire-resistant materials and nonwoven linens are compositions \#2, \#3.

\subsection{Melted Metal Splashes Testing}

Resistance to splashes of melted metal and fire-resistance are main indicators of welder's and metallurgist's protective clothing's quality.

In textile materials and working clothing testing laboratories of personal protection equipment center in Dongguk University (South Korea) a number of studies of textile fire-resistant materials resistance to high temperature was conducted.

Impact of sparkles and melted metal splashes are of special interest. Testing method for tests of materials in a case of melted metal is specified in GOST12.4.237-2007 (ISO 9150:1988) (GOST12.4.237-2007). The method consists of counting number of splashes of melted metal.

10 specimens were fabricated with $120 \times 20 \mathrm{~mm}$ size. Tested specimen was conditioned for at least for 24 hours with relative humidity of $(65 \pm 2) \%$ and $(20 \pm 2){ }^{\circ} \mathrm{C}$ temperature.

In a case of testing according to ISO 9150 each material or multilayer material, used in working clothing, must sustain at least:

- not less than 15 splashes of melted metal with an increase of temperature of sensor behind a tested specimen on $40^{\circ} \mathrm{C}$ for 1 class;

- not less than 25 splashes of melted metal with an increase of temperature of sensor behind a tested specimen on $40^{\circ} \mathrm{C}$ for 2 class;

Obtained values of number of splashes of melted metal and temperature inside a multilayer material are presented in table 6 . Weight of splashes varied from 10.1 to $12.8 \mathrm{~g}$.

Table 6. Values of temperatures during an influence of melted meal on a multilayer material

\begin{tabular}{|c|c|c|c|c|}
\hline $\begin{array}{l}\text { No of } \\
\text { multilayer } \\
\text { material }\end{array}$ & $\begin{array}{l}\text { Composition of layers of multilayer } \\
\text { material }\end{array}$ & $\begin{array}{l}\text { Temperature } \\
\text { of an inner } \\
\text { layer of multilayer } \\
\text { material, }{ }^{\circ} \mathrm{C}\end{array}$ & $\begin{array}{l}\text { Temperature } \\
\text { of inside of } \\
\text { multilayer } \\
\text { material, }{ }^{\circ} \mathrm{C} \\
\end{array}$ & $\begin{array}{l}\text { Number } \\
\text { of melted splashes }\end{array}$ \\
\hline 1 & $\begin{array}{l}\text { FlameFortW280 Protect } \\
\text { Premier FR 350A } \\
\text { Nonwoven material - M-Sh (20) }\end{array}$ & 36.8 & 32 & 25 \\
\hline 2 & $\begin{array}{l}\text { FlameFortW280 Protect } \\
\text { Premier FR 350A } \\
\text { Nonwoven material M-Sh-M (25) }\end{array}$ & 36.8 & 29 & 25 \\
\hline 3 & $\begin{array}{l}\text { FlameFort W280 Protect } \\
\text { Premier FR 350A } \\
\text { Nonwoven material M-Sh-M (1.8) }\end{array}$ & 36.8 & 30 & 25 \\
\hline 4 & $\begin{array}{l}\text { FlameFortW280 Protect } \\
\text { Premier FR 350A } \\
\text { Nonwoven material M-Sh-M-Sh (30) }\end{array}$ & 36.8 & 28 & 25 \\
\hline 5 & $\begin{array}{l}\text { FlameFort W280 Protect } \\
\text { Premier FR 350A } \\
\text { Nonwoven material M-Sh mixed (25) }\end{array}$ & 36.8 & 31 & 25 \\
\hline 6 & $\begin{array}{l}\text { FlameFortW280 Protect } \\
\text { Premier FR 350A } \\
\text { Nonwoven material M-Sh mixed (15) }\end{array}$ & 36.8 & 36 & 25 \\
\hline
\end{tabular}

Results of tests of multilayer materials are presented in Figure 3. 


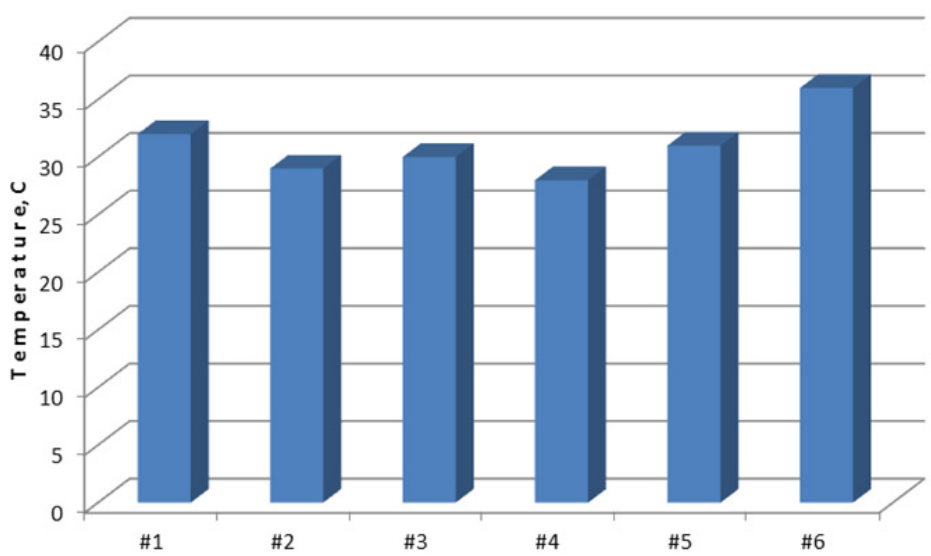

Figure 3. Temperatures of inside of specimens of multilayer materials during an influence of melted metal splashes

Analysis of results (figure 3) shows, that the specimen \#4 possesses higher resistance to high temperatures.

\section{Discussion}

On the basis of the results of conducted studies new compositions of fire-resistant multilayer materials with improved performance are obtained.

General characteristic of selected composition of multilayer fire-resistant material is presented in Table 7.

Table 7. Characteristics of the optimal composition of multilayer material for working clothing

\begin{tabular}{|c|c|c|c|}
\hline Properties and & \multicolumn{3}{|c|}{ Values of properties and characterisitcs of the meaterial } \\
\hline Name of the material & Premier FR 350A & FlameFortW280 & $\begin{array}{l}\text { Nonwoven material stitched } \\
\text { with moleskine }\end{array}$ \\
\hline Code number & $10202 \mathrm{AM}$ & $50402 \mathrm{~K} 14$ & - \\
\hline Composition of fibers & $\begin{array}{l}100 \% \text { cotton }+ \\
\text { antistatic thread }\end{array}$ & $100 \%$ aramide & $\begin{array}{l}\text { (meta-aramide }+ \\
\text { wool) }\end{array}$ \\
\hline Surface density, $\mathrm{g} / \mathrm{m} 2$ & 340 & 430 & 150 \\
\hline Weave & Satinlike $5 / 2$ & Satinlike & Multilayer linen (4 layers) +1 \\
\hline Treatment & PyrovatexTo+HMBO & K14 & - \\
\hline $\begin{array}{l}\text { Breaking } \\
\text { (base/weft) }\end{array}$ & $1200 \mathrm{~N} / 700 \mathrm{~N}$ & $\begin{array}{l}1200 \mathrm{~N} / \\
1200 \mathrm{~N}\end{array}$ & $346 \mathrm{~N} / 205 \mathrm{~N}$ \\
\hline Application & Upper layer & Piece & $\begin{array}{l}\text { Inner stitched detachable } \\
\text { layer with lining }\end{array}$ \\
\hline
\end{tabular}

In the designed working clothing as a lining material detachable, stitched layers of nonwoven material with moleskin are used.

Thus, it is proposed to design new multilayer material for a manufacturing of product using Premier FR 350 A as warp, nonwoven material stitched with moleskin as lining with additional protection from high temperatures and FlameFortW280 as additional protective fabric in a specified places (on front side of jumper, front side of pants, lower parts of sleeves).

For designing of working clothing, protecting from high temperatures and splashes of melted metal, new multilayer materials are proposed, which consists of fire-resistant clothing and newly designed nonwoven linens, produced from second grade wool and aramide fibers, which posses improved heat-resistance properties.

\section{Conclusion}

Nowadays, a lot of companies in Kazakhstan show a demand for more reliable types of working clothing, which 
protect from sparkles and splashes of melted metal and meet other requirements of a customer.

That's why a supply of working clothing to Kazakhstan market is economically profitable and improvement of its quality is an important scientific and industrial problem.

At a pre-project analysis phase a problem was indicated - the lack of working clothes for welders on market, which would fully meet consumers requirements. Despite of variety of fabrics and materials with special fnishing for a protection from high temperatures on market, companies, producing working clothes for welders, do not completely use new materials because of high cost in a case of high performance, and, backwards, use fabrics with lower performance and lower cost.

Thus, the proposed multilayer material consists of: 3 layer nonwoven linen made from wool and aramide fibers and working as an additional fire-resistant lining, for the top part - protective material Premier FR350A, which is whole costume made from, for an additional protection FlameFortW280 Protect was used as protective pieces.

In Kazakhstan there are a number of researches in a field of new composite materials, which require further investigation.

Essential difference of the proposed solution from existing ones in that field consists of an implementation of domestic, natural wool fibers with m-aramid fibers, which allows to significantly decrease the product's cost and in the same time improve fire-protection and performance. In a case of a new implementation of wool fibers in a composition with m-aramid, it is possible to solve a problem of imports substitution in that field.

In the further research it is planned to increase a range of studies in a filed of testing and design of an optimal composition of multilayer materials for working clothing. Because the proposed solution is very simple and allows any interested company to organize mini-production of protective fire-resistant multilayer materials, it is planned to organize manufacturing of such materials.

\section{References}

Dahiya, A., Kamath, M., \& Hegde, R. (2014). Introduction to Nonwovens. Textiles Introduction. Retrieved July 25,2014 , from http://web.utk.edu

Fabrics, K. (2005). Advanced protective materials for clothing, (2005 November 18). Working clothing, 4(31). Retrieved September 20, 2014, from http://www.termolin.com/catalogue.htm

Fomchenkova, L. (2002). Modern materials for working clothing and uniforms. Textile industry, 7, 15-17.

Golubaev, M. (2008). Problems of welder's working clothing design. Working clothing, 4, 43.

GOST. (2007). 12.4.237-2007 (ISO 9150:1988)-Occupational safety standards system. Protective clothing. Methods of testing the material on impact of splashes of molten metal.

GOST. (2007). 50810-95-Fire hazard of textiles. Decorative textiles. Flammability test method and classification.

Gushina, K. (2004). Working clothing. Moscow: Consumer goods industry and food industry.

Kamath, M., Dahiya, A., \& Hegde, R. (2004). Needle Punched Nonwovens. Textiles Introduction. Retrieved July 25, 2014, from http://web.utk.edu

Kel'bert, D. (1971). Labour protection in textile industry. Moscow: Consumer goods industry.

Mokeeva, N., \& Pitzinskaya, O. (2013). Features of welder's working clothing design.

Nonwovens \& Technical, T.(2007). Indian textile. Retrieved July 25, 2014, from indiantextilejournal.com.

Program of the development of consumer products industry in the Republic of Kazakhstan for 2010-2014. (n./d.)

Scott, R. (2005). Textiles for Protection. Woodhead Publishing Limited.

Sheromova, I. (2006). Textile materials. Production, structure, properties: Textbook. Vladivostok.

Suharev, M. (1973). Material science. Moscow: Consumer products industry.

Westex (USA) fire-protective materials. (2005). Working clothing, 4(31).

Working clothing and personal protection equipment. (2004). 3, 23-28.

XM FIRELINE. (2014). Baltiski textile presents fire-resistant fabrics Working clothing, 1(6).

Zhilisbaeva, R., \& Kozhabergenova, K. (2012). Reliability problems in a design of working clothing for metallurgists. Almaty: Almaty Korkem. 
Zhilisbayeva, R. (2011). Peculiarities of Kinetics of New Fire Proof Fabrics Thermal Breakdown. International Conference on Textile Engineering and Materials, China.

\section{Copyrights}

Copyright for this article is retained by the author(s), with first publication rights granted to the journal.

This is an open-access article distributed under the terms and conditions of the Creative Commons Attribution license (http://creativecommons.org/licenses/by/3.0/). 